
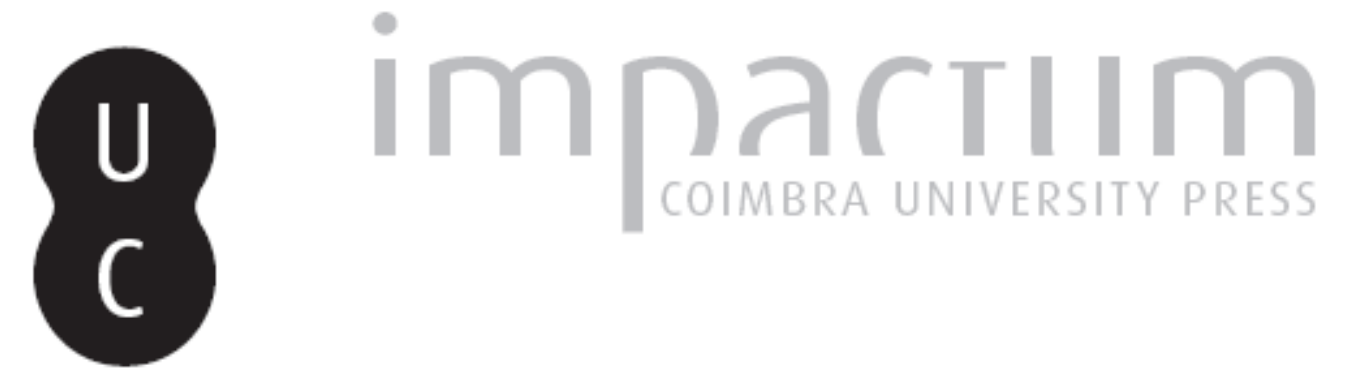

\title{
Fíbulas pré-romanas e romanas do território de Collippo
}

Autor(es): Ruivo, José da Silva

Publicado por: Imprensa da Universidade de Coimbra

URL persistente:

URI:http://hdl.handle.net/10316.2/45498

DOI:

DOl:https://dx.doi.org/10.14195/1647-8657_32_33_24

Accessed : $\quad$ 26-Apr-2023 05:22:36

A navegação consulta e descarregamento dos títulos inseridos nas Bibliotecas Digitais UC Digitalis, UC Pombalina e UC Impactum, pressupõem a aceitação plena e sem reservas dos Termos e Condições de Uso destas Bibliotecas Digitais, disponíveis em https://digitalis.uc.pt/pt-pt/termos.

Conforme exposto nos referidos Termos e Condições de Uso, o descarregamento de títulos de acesso restrito requer uma licença válida de autorização devendo o utilizador aceder ao(s) documento(s) a partir de um endereço de IP da instituição detentora da supramencionada licença.

Ao utilizador é apenas permitido o descarregamento para uso pessoal, pelo que o emprego do(s) título(s) descarregado(s) para outro fim, designadamente comercial, carece de autorização do respetivo autor ou editor da obra.

Na medida em que todas as obras da UC Digitalis se encontram protegidas pelo Código do Direito de Autor e Direitos Conexos e demais legislação aplicável, toda a cópia, parcial ou total, deste documento, nos casos em que é legalmente admitida, deverá conter ou fazer-se acompanhar por este aviso.

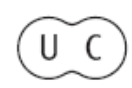




\section{UNIVERSIDADE DE COIMBRA \\ FACULDADE DE LETRAS}

\section{CONIMBRIGA}

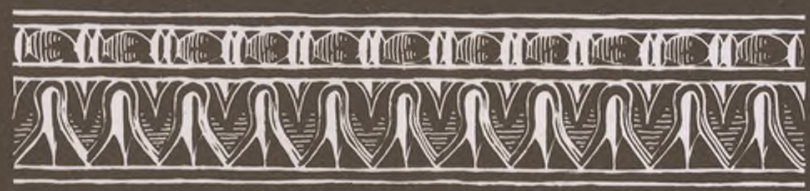

VOLUMES XXXII-XXXIII-1993/94 


\section{José DA Silva RuIVo}

Mestrando em Arqueologia (Universidade do Porto). Bolseiro do PRAXIS XXI

\section{FÍBULAS PRÉ-ROMANAS E ROMANAS DO TERRITÓRIO DE COLLIPPO}

“Conimbriga", XXXII-XXXIII, (1993-1994), p. 371-382

Resumo: Publica-se um conjunto de 13 fíbulas da II Idade do Ferro e da época romana recolhidas nas imediações do local onde teve assento o município lusitano de Collippo. Apesar de a ausência de dados estratigráficos impedir a inserção destes objectos num contexto espácio-temporal preciso, o seu estudo é mais um contributo para o melhor conhecimento da proto-história e da romanização da região.

RÉSUMÉ: On publie un lot de 13 fibules de II ${ }^{\mathrm{e}}$ Âge du Fer et d'époque romaine, trouvées aux alentours du site où a vécu le municipe lusitanien de Collippo. En dépit de l'absence de données stratigraphiques qui empêchent l'insertion de ces objects dans un contexte archéologique défini, leur étude s'affirme comme un nouveau contribut pour une meilleure connaissance de la protohistoire et de la romanisation de la région. 
(Página deixada propositadamente em branco) 


\section{FÍBULAS PRÉ-ROMANAS E ROMANAS DO TERRITORIO DE COLLIPPO}

Encontra-se depositado no Seminàrio de Leiria um conjunto de 13 fíbulas provenientes da colecção arqueológica do pároco do Reguengo do Fetal, Pe. José Oliveira. Estes objectos deram entrada no Museu do Seminário em 1992, após o falecimento daquele sacerdote $(*)$. Quanto à sua proveniência, não temos qualquer indicação segura sobre o local ou locais onde foram encontradas; temos no entanto como dado adquirido o seu achamento em estações arqueológicas localizadas nas imediações do Reguengo do Fetal $\left(^{2}\right)$, nomeadamente em S. Sebastião do Freixo, local que terá sido o assento da cidade romana de Collippo (3).

Todas as peças estudadas são em bronze ou latão $\left({ }^{4}\right)$ encontrándole, na maior parte dos casos, em precário estado de conservação, sendo por isso necessário submetê-las a tratamento adequeado logo que possível.

(') Sobre este conjunto tivemos já oportunidade de dar uma pequena notícia: Ruivo (J. S.), Fíbulas pré-romanas [e romanas] do Museu do Seminário de Leiria, "O Mensageiro", 4/11/1993. Agradecemos à Dra. Sálete da Ponte as sugestões apresentadas na fase final de preparação deste trabalho.

${ }^{2}$ ) Em trabalho escolar da autoria de Maria Luisa Vasconcelos Nogueira 0Colipo, Instituto de Arqueologia, Coimbra, 1966, s. n. ${ }^{\circ}$ de pág.), é apresentada uma fotografia com algumas das fíbulas que publicamos e a indicação de que a n. ${ }^{\circ} 12$ proviria do lugar do Fetal. Esta informação deixa-nos porém algumas dúvidas.

(3) Deste oppidum referido já por Plínio-o-Antigo ( $N H$, IV, 21), não conhecemos todavia significativos vestígios monumentais, apesar dos numerosos achados de materiais arqueológicos efectuados junto à quinta de S. Sebastião (cfr. ALARCão, Roman Portugal, vol. II, fase. 2 - Coimbra \& Lisboa, Aris \& Phillips Ltd., Warminster, 1988, p. 103, $3 / 224)$.

(4) Sobre a composição metálica das fíbulas romanas e da Idade do Ferro, veja-se a título de exemplo RoviRa Llorens (S.), Las fibulas de la Província de Albacete: estudio arqueometalúrgico, in Sanz Gamo (R.), López Precioso (J.) e Soria Combadiera (L.), Las Fibulas de la Província de Albacete, Albacete, 1992, pp. 293-312.

Conimbriga, 32-33 (1993-1994), 371-382 
A peça número 1 identifica-se como sendo uma fíbula anular hispânica, objecto muito frequente em povoados e necrópoles peninsulares da II Idade do Ferro. O nosso exemplar enquadra-se na variante 4a da tipologia de Emeterio Cuadrado, caracterizando-se pelo arco em forma de naveta invertida com uma inflexão de cerca de dois terços do diâmetro e pelo pé largo, por vezes de feição triangular. Um arame enrolado de ambos os lados do aro estabelece a ligação entre este e o pé. Este modelo costuma ser de grandes dimensões certamente por se destinar a prender vestidos de lã $(5)$.

A fíbula anular hispânica representará, na opinião daquele investigador, uma evolução autóctone das fíbulas de Hallstatt D, ocorrida em finais do século VI ou inícios do V a.C. $\left(^{6}\right)$. Opinião diversa é perfilhada por Martín Almagro, que a faz derivar de modelos oriundos do Mediterrâneo Oriental $\left({ }^{7}\right)$.

Recentemente Ruiz Delgado elevou a cronologia da fíbula anular hispânica até aos inícios do século VI a.C. e, eventualmente, até à segunda metade do séc. VII a.C. para alguns exemplares $\left.{ }^{8}\right)$.

$\mathrm{Na}$ opinião de Cuadrado, o tipo 4a parece ser, a par do tipo 1, o modelo mais antigo entre as fíbulas anulares hispânicas, com uma cronologia a rondar os inícios ou a primeira metade do século V a.C. $\left(^{9}\right)$. Este tipo aparece difundido um pouco por toda a Península $\left({ }^{10}\right)$. Em Portugal conhecemos exemplares originários de Conimbriga $\left({ }^{n}\right)$, Alcácer do $\operatorname{Sal}\left({ }^{12}\right)$ e Cabeça de Vaiamonte, Monforte( $\left.{ }^{13}\right)$.

(5) Cuadrado (E.), La fibula anular hispánica y sus problemas, "Zephyrus", Vili (1), Enero-Junio, 1957, p. 15 e 24, fig. 14.

(6) Idem, ibidem, p. 25.

(7) Almagro (M.), Sobre el origen posible de las más antiguas fibulas anulares hispánicas, “Ampurias", XXVIII, 1966, pp. 230-236.

$\left.{ }^{8}\right)$ Ruiz Delgado (M. M.), Fíbulas Protohistóricas en el Sur de la Península Ibérica, Sevilha, 1989, p. 165.

$\left({ }^{9}\right)$ Cuadrado, La fibula anular hispánica y sus problemas, pp. 45-47, 60 e 64, fig. 42 .

$\left({ }^{10}\right)$ Cuadrado, La fibula anular hispánica y sus problemas, p. 46 e fig. 14; Sanz Gamo, López Precioso e Soria Combadiera, Las fíbulas de la Provincia de Albacete, pp. 110-111.

${ }^{(n)}$ Ponte (S.), Les fibules, in Alarcão (J.) e Étienne (R.) (dir.), Fouilles de Conimbriga, VII-Trouvailles diverses, Paris, De Boccard, 1979, p. 114, PI. XXV, n. ${ }^{\circ}$ 13-14.

(12) Ponte (S.), Algumas fibulas de Alcácer do Sal, "O Arqueólogo Portugués", série IV, 3, 1985, pp. 141, 144-145, n. ${ }^{\circ}$ 5-8.

(.3) Ponte (S.), Fíbulas de Vaiamonte (Monforte), "Actas del III Coloquio de Lenguas y Culturas Paleohispanicas”, Salamanca, 1985, p. 139 e 148, Est. I, fig. 5-6. 
1. Fíbula anular hispânica. Tipo Cuadrado 4a. Mantém apenas o anel e o arco, mas este está partido na cabeça e no pé. $\mathrm{O}$ anel é circular, com uma secção em forma de losango, que vai diminuindo progressivamente da cabeça para o pé. A mola, de que restam alguns vestígios, era bilateral, com o arame em forma de fita. $\mathrm{O}$ arco, de secção sobre o triangular, é em forma de naveta invertida. A ligação entre o pé e o anel fazia-se por meio de um fio metálico que estava enrolado de ambos os lados do pé. Não tem fuzilhão.

Comp, do anel: $48 \mathrm{~mm}$; larg.: $45 \mathrm{~mm}$; alt. do arco: $14 \mathrm{~mm}$; peso: 13,8 g.

As fíbulas de pé alto, do tipo $4 \mathrm{~h}$ de Schule $\left({ }^{14}\right)$, mais vulgarmente conhecidas sob a designação de fíbulas "tipo transmontano" a partir dos estudos de J. Fortes $\left({ }^{15}\right)$, estão representadas por três exemplares. Como salientam alguns autores, esta última designação afigura-se de algum modo imprópria para um objecto cuja representatividade, apesar de significativa a Norte do Douro, no actual estado das pesquisas parece ser inferior à que se verifica no Centro e no Sul de Portugal $\left({ }^{16}\right)$. Sem termos a preocupação da exaustividade, basta referir que a Norte do Douro Sálete da Ponte inventariou 29 exemplares, dispersos por mais de quinze estações arqueológicas $\left({ }^{17}\right)$, a que podemos acrescentar 21 oriundos do Castro de Santa Trega, Pontevedra $\left({ }^{18}\right)$, números que não são extraordinariamente significativos quando comparados com os 46 que reunimos para a região centro portuguesa, ou com a mais de meia centena de exemplares da Cabeça de Vaiamonte, Monforte $\left({ }^{19}\right)$. Inclusivamente dever-se-á rever

(14) SCHÜLE (W.), Die Meseta-Kulturen der Iberischen Halbinsel, Berlim, 1969, p. 148, Abb. $59 f$.

(15) ForTes (J.), As fibulas do Noroeste Peninsular, "Portugália", 2, 1905-1908, pp. 20-21.

(16) Nunes (J. C.), Fabião (C.) e Guerra (A.), O acampamento militar romano da Lomba do Canho (Argañil): ponto da situação, "Actas do I Colóquio Arqueológico de Viseu", Viseu, 1989, p. 410.

(17) Ponte (S.), A génese das fibulas do Noroeste Peninsular, "Actas do Seminário de Arqueologia do Noroeste Peninsular", Guimarães, 1980, pp. 118-119, inventaria 17 peças provenientes daquela área geográfica, a que devemos acrescentar mais 6 publicadas pela mesma investigadora em Fíbulas de sítios a Norte do rio Douro, "Lucerna", 1984, pp. 131-132, n. ${ }^{\circ} 24-25,27-28$ e 30-31. Neste último artigo, refere ainda 6 exemplares inéditos (p. 131, notas 92-94).

(18) Caballo Arceo CL. X.), Catálogo dos materiais arqueolóxicos do Museu do Castro de Santa Trega: Idade do Ferro, Pontevedra, 1989, pp. 19-21, n. ${ }^{\circ}$ 17-37.

$\left({ }^{19}\right)$ Santos (M. F.), Fíbulas recolhidas na Cabeça de Vaiamonte (Monforte, Alto Alentejo), "Anais da Academia Portuguesa de História", II Série, voi. 22, Lisboa, 1973, pp. 193-94,sobretudo os nos. 1-67; PonTe (S.), Fíbulas de Vaiamonte, pp. 140-141 e 149-151, Est. I 11, n. ${ }^{\circ} 9-33$.

Conimbriga, 32-33 (1993-1994), 371-382 
a tese da difusão dos seus prototipos a partir da Meseta Castelhana aceite até aqui sem grande contestação $\left({ }^{20}\right)$, em favor da tese das influências mediterrânicas, lentamente difundidas a partir do Sul da Península.

Refira-se que os exemplares que recenseámos para o centro do país estão todos eles - à excepção dos do acampamento romano da Lomba do Canho, Arganil (2 exemplares) - situados a Sul do Mondego (21). As escavações de Conimbriga forneceram 24 exemplares (22), a que juntamos 5 provenientes do Crasto, Soure $\left({ }^{23}\right)$, Idas Dordias, Soure $\left({ }^{24}\right), 2$ do Outeiro da Assenta, Óbidos (25), 6 de Pragança( $\left.{ }^{26}\right)$ e 2 do Castro de S. Salvador, Cadaval $\left({ }^{27}\right)$. Da região de Leiria, para além das 3 peças que ora publicamos, tivemos oportunidade de observar uma outra proveniente de S. Sebastião que se encontra no edifício do Turismo daquela cidade $\left({ }^{28}\right)$.

Por outro lado, também a cronologia deste tipo de fíbula parece suscitar alguns problemas. Schüle situa-a entre finais do século IV a.C. e o terminus do período republicano (29). Contudo, em boa parte dos casos não foi possível determinar o contexto arqueológico das peças e quando tal ocorreu, as datações propostas são muito tardias. É o caso de algumas fíbulas de Conimbriga encontradas nos níveis de construção do forum

(20) SChÜLE (WJ, Las más antiguas fibulas con pie alto y ballesta, Madrid, 1961, pp. 5-6; Ponte, Les fibules, p. 115; Silva (A. C. F.), A Cultura Castreja no Noroeste de Portugal, Museu Arqueológico da Citânia de Sanfins, Paços de Ferreira, 1986, p. 190.

(21) Nunes, Fabião e Guerra, Lomba do Canho, p. 410.

(22) PONTE, Fíbulas pré-romanas e romanas de Conimbriga, "Conimbriga", XII, 1973, pp. 168-171, Est. II-ffl, n. ${ }^{\circ} 5-10$ e c), d), e) e f); Ponte, Les fibules, voi VII, p. 115, PI. XXV, n. ${ }^{\circ}$ 20-25; Ponte, A génese das fibulas do Noroeste Peninsular, p. 118, n. ${ }^{\circ} 44$.

(23) Monteiro, (A.J.N.), Crasto, "Informação Arqueológica", 9, 1994, p. 58, publica 3 exemplares actualmente depositadas no Museu de Soure.

(24) Informação do Dr. A. J. Nunes Monteiro.

(25) CHAVES (L.), Segunda exploração arqueológica do Outeiro da Assenta (Termo de Óbidos), "O Archeologo Português", XX, 1915, p. 265, fig. 8 e p. 269, fig. 14; PonTe, A génese das fibulas do Noroeste Peninsular, p. 118, n. ${ }^{\circ} 36$.

${ }^{(26)}$ Ponte, A génese das fibulas do Noroeste Peninsular, p. 118, n. ${ }^{\circ} 39$; VAsCONCElos (J. L.), Religiões da Lusitânia, vol. Ill, Lisboa, Imprensa Nacional, 1913, p. 127, fig. 54, nota 5; SCHÜLE, Die Meseta-Kulturen, Taf. I11, n. ${ }^{\circ}$ 12; PonTE (S.), Uma colecção de fibulas da Estremadura, "Boletim Cultural da Assembleia Distritai de Lisboa", III série, 88 (1), 1982, p. 216, 219 nota 10, 221, Est. I n. ${ }^{\circ} 3$ e 5.

${ }^{(27)}$ Ponte, Uma colecção de fibulas da Estremadura, p. 216, 221, Est. I n. ${ }^{\circ} 4-5$.

(28) Oleiro (J. M.) e Alarcão (J.), Escavações em S. Sebastião do Freixo (concelho da Batalha), "Conimbriga", Vili, 1969, p. 6.

(29) SCHÜLE, Die Meseta-Kulturen, pp. 149-150. 
flaviano e das termas de Trajano $\left({ }^{30}\right)$, ou da fíbula do Monte Mózinho, Penafiel, surgida num contexto do século I d.C.(31). Já os exemplares encontrados em Numância ( $\left.{ }^{32}\right)$, na Lomba do Canho( $\left.{ }^{33}\right)$, no Crasto ou mais para Sul, na Cabeça de Vaiamonte, no acampamento de Cáceres el Viejo (34) e no castro de Azougada, Moura (35), parecem apontar para uma cronologia mais recuada sem atingir, contudo, o século IV a.C.

Em termos morfológicos, estamos na presença de uma fíbula de pé alto, com um arco em forma de naveta invertida, decorado nas extremidades por anéis ou molduras contínuas, o mesmo acontecendo no apêndice caudal; possui um eixo em bronze ou em ferro, com terminais em forma de disco ou botões decorativos onde se enrola uma mola bilateral simétrica e de corda interior ao arco; o fuzilhão é independente da mola.

2. Fíbula do tipo Schíile 4h. Fragmento em bronze e ferro, conservando o eixo com os discos terminais, a mola - com 14 espirais - e parte do fuzilhão. Comp. da mola: $36 \mathrm{~mm}$; peso: $11,04 \mathrm{~g}$.

3. Fíbula do tipo Schiile 4h. Fragmento em bronze e ferro. $\mathrm{O}$ arco, decorado longitudinalmente por uma moldura em relevo, descreve uma hipérbole. O seu extremo é ornado por molduras anelares. Conserva ainda o olhai com vestígios do eixo de ferro. O fuzilhão está incompleto. A secção é semi-circular.

Comp.: $36 \mathrm{~mm}$; alt.: $20 \mathrm{~mm}$; peso: 10,46 g.

4. Fíbula do tipo Schíile 4h. Fragmento em bronze. O arco é em forma de naveta invertida. A secção é circular. Um dos extremos é ornado por molduras anelares. Comp.: $36 \mathrm{~mm}$; alt.: $23 \mathrm{~mm}$; peso: $13,36 \mathrm{~g}$.

$\mathrm{O}$ fragmento de fíbula $\mathrm{n}^{\circ} 5$ integra-se nas produções de La Tène III. Pertence ao grupo das fíbulas de arco filiforme, com mola bilateral de corda exterior ao arco. Neste caso concreto, a mola tem igual número de

$\left.{ }^{(30}\right)$ Ponte, Les fibules, p. 115.

(31) Almeida (C. A. F.), Escavações no Monte Mózinho, II, 1975-1976, Penafiel, 1977, p. 16, 37, Est. I, fig. 3; PonTe, Fíbulas de sítios a Norte do rio Douro, p. 115.

(32) SCHÜLE, Die Meseta-Kulturen, p. 148, Abb. 59f.

(33) Este local terá sido ocupado por volta de meados do século I a.C. (cfr. Nunes, Fabião e Guerra, Lomba do Canho, p. 411).

${ }^{\left({ }^{34}\right)}$ ULBert, (G.), Cáceres el Viejo. Ein spätrepublikanisches legions lager in Spanisch-Extremadura, Madrider Beitrage, Band 11, Mainz am Rhein, 1984, Taf. 9, n. ${ }^{\circ} 35-41$. O acampamento foi abandonado na época das guerras sertorianas (80-72 a.C.).

(35) Gamito (T. J.), Social complexity in Southern Iberia 800-300 B.C. The case of Tartessos, BAR IS 439, Oxford, 1988, fig. 49. 
voltas dos dois lados. Um fragmento em tudo semelhante ao nosso foi encontrado em Conimbriga, numa camada de abandono do habitat indígena na zona da palestra das termas de Trajano ( $\left.{ }^{36}\right)$. Outros exemplares deste tipo foram encontrados naquela cidade em estratos do século I e inícios do II d.C. ( $\left.{ }^{37}\right)$. As escavações de Miróbriga forneceram duas fíbulas desta classe, mas não existe qualquer referência ao seu contexto estratigráfíco ${ }^{(38)}$.

5. Fíbula de La Tène III. Fragmento que conserva a mola bilateral de corda exterior ao arco (4 voltas). A mola é criada a partir do fuzilhão que se apresenta incompleto. $\mathrm{O}$ arco, a mola e o fuzilhão eram feitos de um só arame. Comp, do fuzilhão: $33 \mathrm{~mm}$; larg. da mola: $12 \mathrm{~mm}$; peso: 4,82 g.

Também nas produções de La Tène III se integram as fíbulas do tipo Nauheim, de que constam três exemplares no nosso inventário (n. ${ }^{\circ} 6,7$ e 8). Esta denominação anda associada à necrópole de Bad Nauheim (Frankfurt, Alemanha), onde nos inícios do século se descobriram vários exemplares que, pelas afinidades patenteadas entre eles, acabariam por estar na base de um nova tipologia $\left({ }^{39}\right)$.

Estruturalmente, as fíbulas de Nauheim caracterizam-se por possuir o arco, a mola e o fuzilhão feitos de um único fio metálico. No modelo mais clássico, o arco é de feição triangular e pouco encurvado; a mola é bilateral, com quatro voltas e de corda interior ao arco; o pé é univazado, contíguo, variando de acutângulo a rectangular e o fuzilhão é recto $\left({ }^{40}\right)$.

Estas produções estão relativamente bem documentadas no centro e no sul do território português, em locais como Lomba do Canho $\left({ }^{41}\right)$, Conimbriga $\left({ }^{42}\right)$, Casal da Mota, Nazaré $\left({ }^{43}\right)$, Pedrão, Setúbal $\left({ }^{44}\right)$, Miró-

( $\left.{ }^{36}\right)$ Cfr. Ponte, Les fibules, p. 116 e PI. XXVI, n. ${ }^{\circ} 35$.

${ }^{(37)}$ Idem, ibidem, p. 116 e PL XXVI, n. ${ }^{\circ} 34$ e 37.

${ }^{(38}$ Ponte (S.), As fibulas de Miróbriga, "Setúbal Arqueológica", V, 1979, pp. 196-197, Est., n. ${ }^{\circ} 7-8$.

(39) Nunes (J. C.), Fíbulas do tipo Nauheim no castro da Lomba do Canho, em Arganil, "Revista de Guimarães", LXIX, 1959, p. 397.

(40) Idem, Ibidem, pp. 398-399; PonTe, Fíbulas do distrito de Setúbal, pp. 317-318.

(41) NunEs, Fíbulas do tipo Nauheim no castro da Lomba do Canho, pp. 397-416;

Nunes, Fabião e Guerra, Lomba do Canho, pp. 410 e 424, fig. 9, n. ${ }^{\circ} 4$.

(42) PONTE, Les fibules, pp. 117-118, 124, PI. XXVI, n. ${ }^{\circ}$ 41-46; PONTE, Fíbulas de Conimbriga, pp. 176-179, Est. IV-V, n. ${ }^{\circ} 15-17$ e 19-21.

$\left.{ }^{(43}\right)$ Ponte, (S.), Fíbulas do Museu Etnográfico e Arqueológico Dr. Joaquim Manso (Nazaré), "Conimbriga", 23, 1984, pp. 93-95, fig. 5-6.

$\left.{ }^{44}\right)$ PonTe, Fíbulas de Setúbal, pp. 317-318, 321, fig. 1, n. ${ }^{\circ} 2-3$. 
briga (45) e Cabeça de Vaiamonte(46). Apesar de os contextos cronológico-estratigráficos serem por vezes um pouco imprecisos, sabemos que sua utilização parece prolongar-se até meados do século II d.C. em vários locais do mundo romano $\left({ }^{47}\right)$.

6. Fibula de Nauheim. O arco alongado e laminar, de feição triangular, caracteriza-se por um alteamento do ombro. A mola bilateral, de corda interior ao arco, consta de 4 voltas. A secção do aro é rectangular. Pé, descanso e fuzilhão desapareceram.

Comp.: $72 \mathrm{~mm}$; alt.: $31 \mathrm{~mm}$; peso: $16,97 \mathrm{~g}$.

7. Fíbula de Nauheim. Idêntica à anterior, mas de mais pequenas dimensões. A mola, fracturada, conserva apenas duas voltas. Possui parte do pé, embora sem descanso.

Comp.: $65 \mathrm{~mm}$; alt.: $22 \mathrm{~mm}$; peso: $8,45 \mathrm{~g}$.

8. Fíbula de Nauheim. Fragmento que conserva a mola bilateral de corda interior ao arco, o eixo e parte do ombrai do arco. O arco é de secção rectangular, com uma nervura longitudinal ao centro, ladeada por um fino tracejado.

Comp.: $18 \mathrm{~mm}$; peso: $3,10 \mathrm{~g}$.

Os números 9 e 10 integram-se no grupo das fíbulas de "Aucissa", designação que encontrou a sua origem no nome de um dos fabricantes mais activos deste modelo $\left({ }^{48}\right)$. Este tipo está já presente nas Gálias nas últimas décadas do século I a.C., em locais como Bibracte, Gergovia, Haltern ou Hofheim, e embora tradicionalmente a sua cronologia seja fixada até ao periodo flaviano $\left({ }^{49}\right)$, parece prolongar-se no caso de algumas variantes até ao século II.

Colocando de parte a questão da origem gaulesa ou italiana desta fíbula $^{\wedge 0}$ ), podemos dizer que ela se caracteriza genericamente por um

${ }^{(45)}$ Ponte, Fíbulas de Miróbriga, p. 197, 200, fig. 9.

(46) SAntos, Fíbulas recolhidas na Cabeça de Vaiamonte, p. 196, nos. 68, 74, 75, 111-120, 148-149, 151, 153, 158, 225-231; PONTE, Fíbulas de Vaiamonte, pp. 144-146, 152-153, Est. III-IV, n. ${ }^{\circ}$ 55-74.

$\left({ }^{47}\right)$ SIMPSON (G.), Some British and Iberian penannular brooches and other early types in the Rhineland and the 'Decumates Agri', "The Antiquaries Journal", LIX (2), 1979, p. 333.

(48) Lerat (L.), Catalogue des collections archéologiques de Besançon. II - Les fibules gallo-romaines, "Annales Littéraires de 1' Université de Besançon", 2e Série, Tome III, fase. 1, Archéologie, 3, Besançon, 1956, p. 19.

(49) Idem, ibidem, p. 23.

$\left.{ }^{50}\right)$ Veja-se a discussão desta problemática em Ponte, Fíbulas romanas e pré-romanas de Conimbriga, p. 26. 
arco semi-circular de feição triangular, uma cabeça de charneira, o pé curto rematado por um botão esférico ou cónico, o descanso triangular e o fuzilhão recto.

A partir das fíbulas das escavações da cidade britânica de Camulodunum, Colchester, estabeleceram-se três variantes da fíbula de Aucissa, conhecidos por Camulodunum $17 \mathrm{~A}, \mathrm{~B}$ e $\mathrm{C}\left({ }^{51}\right)$.

O nosso exemplar $\mathrm{n} .^{\circ} 9$ integra-se no tipo $17 \mathrm{~A}$, que se caracteriza por um arco laminar de feição triangular, que realiza com o pé - muito reduzido - um angulo obtuso. Em Conimbriga está presente nos níveis de construção do forumflaviano e das termas trajânicas $\left({ }^{52}\right)$.

$\mathrm{O}$ n. ${ }^{\circ} 10$ parece integrar-se no tipo $17 \mathrm{C}$. Neste grupo o arco é semicircular, a decoração pauta-se frequentemente pela sobriedade, a placa toma-se mais pequena, a carteia raramente excede a largura do arco e o pé toma-se insignificante. Esta forma encontra-se em vários locais do mundo romano, com uma cronologia que medeia entre o período claudiano e os inícios da dinastia antonina ( $\left.{ }^{53}\right)$.

9. Fíbula de Aucissa. Arco laminar de feição triangular, encurvado. A seç̧ão é rectangular. $\mathrm{O}$ arco é debruado nas extremidades por um tracejado quase imperceptível. A cabeça é de charneira. O pé conserva apenas o arranque do descanso. Tem fuzilhão.

Comp.: $37 \mathrm{~mm}$; alt.: $15 \mathrm{~mm}$; peso: $2,83 \mathrm{~g}$.

10. Fíbula de Aucissa. $\mathrm{O}$ arco, torcido junto à placa, é semi-circular e tem secção triangular. A placa é quadrangular e alta. O pé é coroado por um botão, o descanso é triangular e alto. Não tem fuzilhão.

Comp.: $62 \mathrm{~mm}$; alt.: $30 \mathrm{~mm}$; peso: $6,35 \mathrm{~g}$.

O nosso estudo termina com a apresentação de três fíbulas anulares romanas que se integram no tipo B1 de Fowler (54). Caracterizam-se por ter as extremidades do aro em forma de molduras anelares ou de botões cónicos, por vezes facetados. $\mathrm{O}$ fuzilhão é recto e a cabeça em anel.

A origem das fíbulas anulares ou em ómega, como também são conhecidas, é bastante discutida. Para Fowler teriam surgido em Inglaterra,

(51) Hawkes (C. F. C.) e Hull (M. R.), Camulodunum. First report on the excavations at Colchester 1930-1939, Oxónia, 1947, p. 322 e segs.

(52) PonTe, Les fibules, p. 119, 124, PI. XXVII, n. ${ }^{\circ}$ 52-54.

(«) Ponte, Les fibules, p. 120, 125, PI. XXVIII, n. ${ }^{\circ}$ 61-65; SIMPSON, Some British and Iberian penannular brooches, p. 333.

${ }^{(54)} \quad$ FOWLER (E.), The origins and development of the penannular brooch in Europe, "Proceedings of the Prehistoric Society", XXVI, 1960, p. 151, fig. 1. 
já que o seu tipo mais arcaico, o $\mathrm{Aa}$ - representado pelas fíbulas de aro interrompido — aparece associado a materiais do séc. Ili a.C. e é independente dos achados mais recuados feitos nos castros peninsulares (55).

Contudo, os dois modelos mais antigos da fibula de aro interrompido até agora descobertos provém de França, das regiões do Aisne e do Mame, remontando a sua cronologia ao século V a.C. $\left({ }^{56}\right)$. Hawkes admite que tenham influenciado as produções britânicas, porém o desenvolvimento destas pode ter-se processado de forma autónoma de c. 400 a.C. em diante $\left({ }^{57}\right)$. Ainda segundo aquele especialista, as primeiras fíbulas anulares da Península teriam sido introduzidas a partir de protótipos britânicos $\left.{ }^{58}\right)$. Por seu tumo, Sálete da Ponte faz derivar este modelo das fivelas anulares de aro fechado tão comuns nos castros lusitanos $\left({ }^{59}\right)$. As fíbulas anulares estão presentes em numerosos locais do mundo romano, com uma cronologia variável que vai sobretudo do século I d.C. à primeira metade do século III $i^{60}$ ), embora Ettlinger a estenda ao século IV (61). Em Conimbriga, os exemplares fornecidos pelas escavações integram-se nesta cronologia, com particular incidência nos períodos flaviano e trajânico $\left({ }^{62}\right)$.

11. Fíbula anular romana. $\mathrm{O}$ aro e a secção são circulares. Um dos extremos do aro termina em botão cónico, o outro está fracturado. Não tem fuzilhão. Comp.: $27 \mathrm{~mm}$; larg.: $27 \mathrm{~mm}$; peso: 4,16 g.

12. Fíbula anular romana. $O$ aro e a secção são circulares. As extremidades do aro são rematadas por botões cónicos. O fuzilhão está intacto.

Comp.: $50 \mathrm{~mm}$; larg.: $45 \mathrm{~mm}$; peso: 25,21 g.

13. Fíbula anular romana. $O$ aro e a secção são circulares. Os extremos do aro terminam em molduras anelares quase imperceptíveis devido ao desgaste. Não tem fuzilhão.

Comp.: $29 \mathrm{~mm}$; larg.: $29 \mathrm{~mm}$; peso: $2,31 \mathrm{~g}$.

(55) Idem, ibidem, p. 155.

(56) SIMPSON, Some British and Iberian penannular brooches, pp. 319-320.

${ }^{57}$ ) HAWKeS (C. F. C.), Penannular brooches Fowler Aa, B, and $C$ in Britain and the Iberian Peninsula, in SIMPSON, Some British and Iberian penannular brooches, p. 327 .

(58) Idem, ibidem, p. 328.

(59) PonTe, Les fibules, p. 189.

(60) Ponte, Les fibules, p. 120. Iniesta SAnMartín (A.), Las fíbulas de la region de Murcia, Editora Regional Murciana, Murcia, 1983, p. 200.

(61) ETtLinger (E.), Die Römischen Fibeln in der Schweiz, Berna, 1973, p. 30

(62) Ponte, Les fibules, p. 120 
A publicação deste conjunto de fíbulas pretende dar uma pequena achega ao conhecimento da proto-história e da romanização do território coliponense. Assim, enquanto a presença de peças com cronologias supostamente recuadas - sobretudo uma fíbula anular hispânica ou as fíbulas do tipo $4 \mathrm{~h}$ de Schíile - poderá testemunhar, de alguma forma, a integração da região nos circuitos da Idade do Ferro ( ${ }^{63}$ ), outros exemplares retratarão já um passo posterior da história local, o da assunção da romanidade, independentemente de a ausência de dados sobre o conjunto impedir a sua inserção num contexto espacial e temporal preciso.

(63) Talvez em sintonia com a fixação de populações túrdulas na região por volta do séc. IV ou III a.C. Sobre esta problemática, vejam-se AlARCão (J.), O Domínio Romano em Portugal, Mem Martins, Europa-América, 1988, pp. 65-66 e SILVA (A. C. F.), Proto-História do Norte e Centro de Portugal, in Silva (A. C. F.) e Gomes (M. V.), Proto-História de Portugal, Universidade Aberta, Fisboa, 1992, pp. 45-47. 

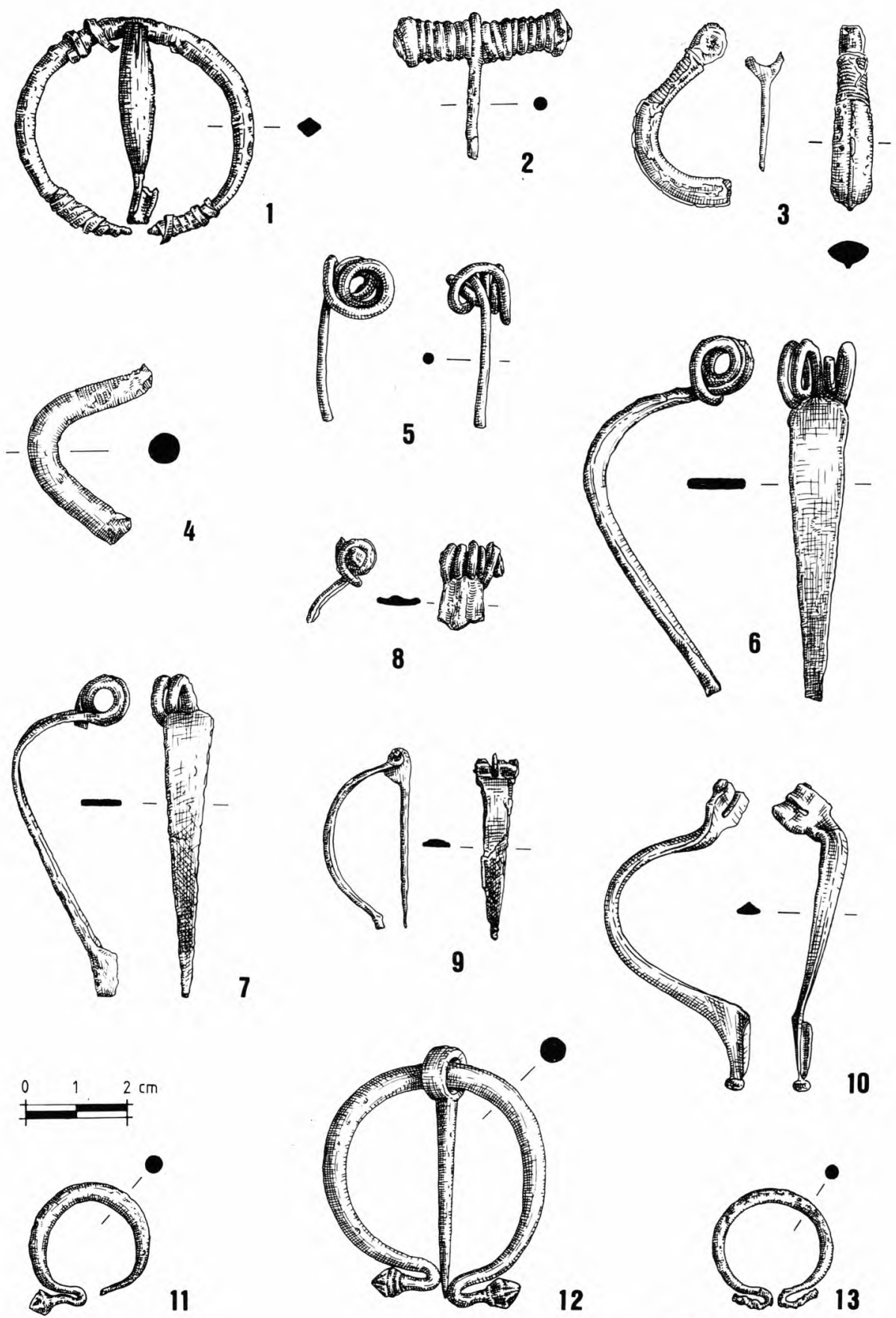

12

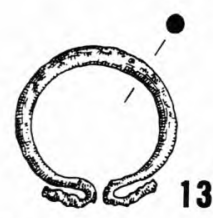
DES: JOĀD Pocirito 